\title{
Research on the Main Body of Poverty Alleviation by Green Science and Technology in Rural China
}

\author{
Ni Yuan \\ University of Science \& Technology of China, China, Anhui, Hefei, 230026, China \\ * E-mail of the corresponding author: nyustc@mail.ustc.edu.cn
}

\begin{abstract}
Based on the perspective of green development, this paper analyzes the relevant literature on the construction of governance capacity and modernization of governance system of poverty alleviation through science and technology in China's rural areas, accurately positioning the relevant concepts, and combining with the geographical distribution of poverty-stricken areas in China, discusses the change of governance function of poverty alleviation through science and technology, clearly defines and puts forward the main body and process of poverty alleviation governance in rural China through science and technology.
\end{abstract}

Keywords: Green development; Poverty alleviation through science and technology; The main body of poverty alleviation

DOI: $10.7176 / \mathrm{JEES} / 10-8-06$

Publication date:August $31^{\text {st }} 2020$

With China's economic and social development and the acceleration of industrialization, informatization and urbanization, in order to protect the bottom line of rural ecological environment and play an important role of science and technology in rural poverty alleviation, we need to base on the green development concept. This study is proposed in this context.

\section{Introduction}

1.1The overall layout of the country

In the process of China's economy changing from high-speed growth stage to high-quality development stage, pollution prevention and environmental control are very important. Due to the low level of agricultural productivity, low awareness of environmental protection, and limited extension of agricultural science and technology, complex ecological environment problems have been accumulated in the process of rural poverty alleviation. The destruction and pollution of agricultural ecological environment not only affect the sustainability of poverty alleviation, but also pose a potential threat to the health of farmers. The more 300 million mu of arable land in China has been polluted by heavy metals, which is not suitable for grain production.

Agricultural science and technology innovation is an integral part of the national innovation system, which takes agricultural technology innovation as the core driving force of agricultural economic and social development. Agricultural technology innovation plays an important role in the development of agricultural technology.

\subsection{Development direction and trend of agricultural poverty alleviation}

It is an important goal of China at the present stage that the poor people and regions in rural areas enter the welloff society in an all-round way together with the whole country. With the steady progress of the strategy of poverty alleviation, poverty alleviation has made comprehensive progress, tens of millions of poor people have been lifted out of poverty, and the incidence of poverty has dropped sharply. A number of poverty-stricken counties have been successfully lifted out of poverty all over the country.

Table 1-1. The incidence of poverty in China in recent 40 years

\begin{tabular}{c|c|c|c|c|c|c|c}
\hline \hline Year & $\begin{array}{c}\text { Poverty } \\
\text { standard at } \\
\text { current price } \\
\text { (yuan / year } \\
\text { person) }\end{array}$ & $\begin{array}{c}\text { Incidence of } \\
\text { poverty } \\
(\%)\end{array}$ & $\begin{array}{c}\text { Scale of } \\
\text { poor } \\
\text { population } \\
(\mathbf{1 0 0 0 0 )}\end{array}$ & Year & $\begin{array}{c}\text { Poverty } \\
\text { standard at } \\
\text { current price } \\
\text { (yuan/ } \\
\text { year } \text { person) }\end{array}$ & $\begin{array}{c}\text { Incidence } \\
\text { of poverty } \\
(\%)\end{array}$ & $\begin{array}{c}\text { Scale of } \\
\text { poor } \\
\text { population } \\
(\mathbf{1 0 0 0 0 )}\end{array}$ \\
\hline $\mathbf{1 9 7 8}$ & 366 & 97.5 & 77309 & $\mathbf{2 0 1 1}$ & 2536 & 12.7 & 12238 \\
\hline $\mathbf{1 9 8 0}$ & 403 & 96.2 & 76542 & $\mathbf{2 0 1 2}$ & 2625 & 10.2 & 9899 \\
\hline $\mathbf{1 9 8 5}$ & 482 & 78.3 & 66101 & $\mathbf{2 0 1 3}$ & 2736 & 8.5 & 8249 \\
\hline $\mathbf{1 9 9 0}$ & 807 & 73.5 & 65849 & $\mathbf{2 0 1 4}$ & 2800 & 7.2 & 7017 \\
\hline $\mathbf{1 9 9 5}$ & 1511 & 60.5 & 55463 & $\mathbf{2 0 1 5}$ & 2855 & 5.7 & 5575 \\
\hline $\mathbf{2 0 0 0}$ & 1528 & 49.8 & 46224 & $\mathbf{2 0 1 6}$ & 2952 & 4.5 & 4335 \\
\hline $\mathbf{2 0 0 5}$ & 1742 & 30.2 & 28662 & $\mathbf{2 0 1 7}$ & 3070 & 3.1 & 3046 \\
\hline $\mathbf{2 0 1 0}$ & 2300 & 17.2 & 16567 & $\mathbf{2 0 1 8}$ & 3300 & 1.7 & 1660 \\
\hline \hline
\end{tabular}


However, in the face of the complexity of the remaining poor households and the instability of the new poverty relief households, "post poverty alleviation era" is coming. It is worth in-depth study to realize the sustainable poverty alleviation and seamless connection between poverty alleviation and rich people. In the post poverty alleviation era, most of the poverty phenomena come from areas with poor natural resource endowment and weak agricultural management foundation. The poverty alleviation work in this area will be the difficulty of "Rolling Stones climbing mountains and climbing over the ridge", especially for the special groups such as physically disabled people, the elderly who are lonely and widowed, and the rural poor groups who lack technical skills and training conditions.

\subsection{The needs of the construction of national poverty alleviation governance system}

It is of great significance for the times that the construction of rural poverty alleviation governance capacity matches the modernization of national governance system. On the one hand, rural poverty alleviation and enriching the people need to be integrated. With the deepening of governance capacity building, the working ideas of poverty alleviation and enriching the people are gradually unified, and the relationship between poverty alleviation and development is also closer. It is necessary to gradually form the continuity and unity of the governance system, management system and operation mode of the two aspects; on the other hand, there is a need for policy coordination between poverty alleviation through science and technology and national macro governance. The important component of public governance system is the policy system, which promotes the promotion and application of science and technology in agricultural development. The policies in the fields of agricultural science and technology, agricultural environmental protection and agricultural industrialization are the organic components of the national policy governance system. The significance of policy coordination is to ensure the stability and continuity of the national governance system.

Science and technology add traction to rural poverty alleviation, and green development provides carrying capacity for rural poverty alleviation. The so-called science and technology traction force, which provides a sustained driving force for the agricultural population to increase income, avoids the phenomenon of "short-term poverty alleviation" and "one-time poverty alleviation", gradually improves the overall quality of agricultural population and stimulates the creativity of agricultural human resources. The driving force of science and technology provides a driving force for rural poverty alleviation, which is different from the traditional factor input. Let science and technology and innovation drive the development of rural agriculture. Its input-output efficiency may not be instant, but the traction effect of science and technology driving farmers' income increase and agricultural prosperity is gradually amplified, and it is multi-level and multi-disciplinary. The so-called green development carrying capacity draws a bottom line for the ecological environment. The carrying capacity of green development delineates the bearing range for rural poverty alleviation. Combined with the carrying capacity of land resources, water resources and air resources in different rural areas, it provides scientific decision-making scheme and governance mode for rural poverty alleviation, internalizes external problems, and integrates environmental resources into national governance decision-making.

\section{Literature research on poverty alleviation through agricultural science and technology}

Green development is an economic development mode guided by resource saving and environment-friendly. In the past decade, under the dual constraints of bearing pressure of environmental resources and increasing resource consumption, the research on the concept, approach, mode and effect of green development has gradually become a hot field. Looking at the literature situation of "green development" from 2009 to 2019 on CNKI platform, it can be found that the previous "green development" literature volume and cited volume are slow with 2015 as the cutoff point In 2015, the number of green development literature reached 857 , with a growth rate of $59 \%$. The number of green development Chinese literature was cited 379 times, with a growth rate of $34 \%$. Since then, the domestic academic circles have been deepening the research on green development, and the research results have increased rapidly.

In 1986, as the first time that the State Science and Technology Commission put forward the measure of "poverty alleviation through science and technology", it proposed to implement the anti-poverty measures in rural areas from relief type to relying on science and technology development type. Since then, "science and technology poverty alleviation" has become an important part of the Chinese government's development and poverty alleviation.

Based on the analysis of Chinese literature on poverty alleviation through science and technology in recent 30 years, the trend of literature quantity and cited quantity shows three stages. The first stage is from 1988 to 2007 , nearly 20 years. In the past 20 years after China put forward the measures of poverty alleviation through science and technology in 1986, the domestic research on poverty alleviation through science and technology is lagging behind. As the initial stage of poverty alleviation through science and technology, people have experienced longterm practice and exploration, and have not made a major breakthrough in the effectiveness of poverty alleviation through science and technology due to the constraints of historical environment and economic conditions. The 
second stage, from 2007 to 2012. In this period, China has joined the WTO. The new division of labor in the international trade system promotes the corresponding adjustment of China's agricultural modernization process. Under the international competition mechanism, the modernization of agricultural industry is forced to develop, and the potential of agricultural science and technology is stimulated Agricultural science and technology is considered as a new driving force for farmers to reduce poverty and increase their income, so relevant research shows a steady growth trend. The third stage, from 2012 to now. During this period, the domestic research on poverty alleviation through science and technology has increased rapidly, especially in 2016 and after, which is the superposition effect of China's poverty alleviation strategy and innovative development concept. On the one hand, farmers have higher requirements and standards for poverty reduction and income increase, and they must ensure the quality and sustainability of poverty alleviation. On the other hand, with the continuous emergence of scientific and technological achievements, the agricultural industry has been greatly improved The application scenarios of achievements in forestry, biology, environmental protection, materials, information and other fields in the field of agricultural modernization are more abundant.

\section{Research on related concepts of poverty alleviation through agricultural science and technology}

In order to study the current situation of poverty alleviation by science and technology in rural China and analyze the governance approaches and optimization methods, relevant concepts need to be defined and analyzed.

\subsection{Definition of green development of Agriculture}

It is necessary to clarify the connotation of agricultural green development in the study of rural science and technology poverty alleviation. Green development focuses on solving the problem of harmony between man and nature. Agriculture has a specific natural landscape and social and economic conditions. The place where the laborers who are engaged in agricultural production live is different from that in cities and towns. Compared with the traditional development, the green development of agriculture needs to face the dual constraints and challenges of rural environmental capacity and agricultural resource stock. From the perspective of modern public economics, the mode of agricultural green development should include two aspects: on the one hand, when determining the average cost of rural production, the environmental cost should be included in the internal cost of agricultural development for evaluation, with the purpose of internalizing the negative externality, so that the agricultural development subject can fully consider the hidden cost caused by the destruction of rural production and living environment, and the agricultural development On the other hand, in the allocation of agricultural social resources, the rural environmental resources as an important strategic resource similar to human resources, material resources and information resources are incorporated into the agricultural economic system resource stock for consideration and comprehensive allocation, and the optimal allocation of agricultural environmental resources is oriented to coordinate the rural economic and social development Macro resource allocation. In the process of economic and social development, if we break through the rural environmental carrying capacity and environmental resource stock, we may face great environmental risks, ranging from slowing down the regional economic development to serious social and economic crisis. China's guiding ideology for green development of agriculture is gradually clear, and the construction positioning is more accurate and the starting point is more comprehensive. This paper analyzes the connotation of ecological civilization from the perspective of historical materialism, and holds that ecological civilization means civilization, and ecological civilization is an important part of Chinese civilization.

\subsection{Definition of poverty alleviation through science and technology}

Poverty alleviation through science and technology is considered as a sign of the transformation from the simple relief poverty alleviation to the poverty alleviation relying on science and technology development. The application of science and technology to reform the closed small-scale peasant economic model in poverty-stricken areas, improve the scientific and cultural quality of farmers, improve their resource development level and labor productivity, promote the development of commodity economy, and speed up the pace of farmers getting rid of poverty and becoming rich. China's current poverty alleviation model can be summarized into two categories: "blood transfusion" poverty alleviation model and "blood making" poverty alleviation model. There are great differences between the two types of poverty alleviation models, and there are also close links. The traditional poverty alleviation mode is mainly "blood transfusion type" poverty alleviation, with funds and security materials as the main input resources. The application of this mode often occurs in the initial stage of poverty alleviation, its purpose is to "relief" the elderly, the weak, the orphans and the disabled and other special poverty-stricken people and the poverty-stricken areas with extremely backward resource endowment, so as to realize the basic living and production; the scientific and technological poverty alleviation is based on the "blood production type" "Poverty alleviation is mainly to guide indirect investment in science and technology, cultural resources, industrial resources, etc., to provide technical solutions, marketing channels, education platforms and employment channels for the poverty-stricken areas and the poor population, promote the development of characteristic industries and the iteration of agricultural science and technology in poor areas, improve the output efficiency of poor farmers, 
protect the rural environment and maintain the villages and towns Sustainable economic growth. The governance of poverty alleviation through science and technology emphasizes the development mode and operation mechanism constructed under the guidance of governments at all levels in order to gather the scientific and technological forces and innovative resources from all aspects of society to the poor areas and the poor population. All kinds of science and technology poverty alleviation subjects, including the government, cooperate with each other and achieve the goal of unity. Through the investment of agricultural science and technology related policies, funds, human resources and other resources, the poverty-stricken areas and the poor population can be lifted out of poverty in an all-round, high-quality and sustainable way.

\subsection{The connotation of public poverty alleviation governance}

With the development of the national economy, the focus of poverty alleviation in rural areas has changed from providing enough food and clothing to getting rid of poverty and enriching the people. It is of great significance for strengthening the construction of social governance system and promoting the quality improvement of poverty alleviation through science and technology to carry out research on poverty alleviation governance and promote the layout of poverty alleviation governance in the national poverty alleviation governance system. First of all, science and technology poverty alleviation governance is to realize the change of poverty alleviation governance concept from management to service. The development and application of science and technology and its possible social and economic environmental benefits are the result of the unity of inevitability and contingency, which is not achieved by simply relying on management and control. Creating a good environment for the promotion and application of agricultural scientific and technological achievements is a necessary way to promote agricultural development The improvement of service level can greatly promote the release of innovation and development bonus in rural areas. Secondly, the construction of scientific and technological poverty alleviation governance capacity helps to improve the main body of poverty alleviation, optimize the cooperation mode and sharing mode between the government and social forces, especially in the aspects of breaking through capital barriers, location barriers, policy barriers and so on, so as to effectively improve the initiative of social forces to participate in poverty alleviation and development; thirdly, the governance of poverty alleviation through science and technology promotes the construction of intelligent agricultural system From scientific discovery to technology formation and then to technology application, each link has formed a complete system. The development of smart agriculture is inseparable from the systematic construction mode. With the deepening of the integration of government governance and agricultural technology, China's smart agriculture and modern agricultural system will accelerate development. Finally, the construction of science and technology poverty alleviation governance system promotes the reform of poverty alleviation governance assessment and reward and punishment system, and the assessment indicators of poverty alleviation effectiveness have changed. Under the guidance of high quality and sustainable poverty alleviation, accuracy and sustainability of poverty alleviation have become important assessment aspects.

\section{The change of governance function of public poverty alleviation in China}

4.1 The transformation of government's function of poverty alleviation in the early stage of market economy Market economy system refers to the economic operation system that allocates social resources through market mechanism. In 1978, China carried out reform and opening up. Under the market economy system, the government's function transformation of poverty alleviation mainly focuses on the establishment of agricultural market subject, improvement of agricultural market system and optimization of agricultural distribution mechanism.

Establish the main body of agricultural market. Under the market economy system, the government should adjust the relationship among state-owned enterprises, collective enterprises and private enterprises in the agricultural field, implement the separation of government and enterprise, push agricultural enterprises into the market, and establish the dominant position of agricultural enterprises in the agricultural market. At the same time, according to the characteristics of agricultural production, the government should build a corresponding policy support system to improve the system of modern agricultural enterprises and ensure the normal operation of agricultural market subjects.

Improve the agricultural market system. Under the market economy system, the government's anti-poverty governance has guaranteed the smooth operation of the agricultural market economy, constructed the institutional framework for the operation of the agricultural market, cultivated the agricultural labor market, agricultural information market, agricultural science and technology market, agricultural environmental resources market, agricultural financial market and so on. It not only includes the narrow rural market system, such as the establishment and transformation of rural consumer goods flow It also includes the effective transmission of agricultural product price mechanism in broad sense, the efficient transformation of agricultural intellectual property rights, the accurate implementation of agricultural Inclusive Finance, the timely and full payment of agricultural workers' wages, and the rational competition of agricultural enterprises. 
Optimize the agricultural distribution mechanism. The transformation of economic system brings about the adjustment of income distribution mechanism. Government governance promotes the optimization of agricultural distribution mechanism, guarantees agricultural production and gradually increases farmers' income. To analyze the optimization of agricultural distribution mechanism, we need to combine three factors that affect agriculture: first, affected by the natural environment, agricultural production has a high uncertainty, so the government's poverty alleviation governance should play a role in income distribution, encourage the collection and storage in the agricultural harvest year, and make up for the deficit reasonably in the agricultural poor harvest year; second, affected by asymmetric information Impact, agricultural production has a certain convergence and follow-up effect. When a certain agricultural product is in short supply, it is easy to have a swarm of bees to supplement and replant. When the supply exceeds the demand, the enthusiasm of planting and breeding will greatly reduce the withdrawal from the market. The government should reasonably use the policy baton to mitigate the risk of agricultural information in response to such difficulties. Third, affected by the cyclical nature of agricultural production, agriculture is affected by the cyclical nature of agricultural production Production is difficult to improve the commodity rate of products by increasing equipment and manpower as industrial products.

\subsection{Government's poverty alleviation function optimized in recent years}

Adjust the guidance of poverty alleviation and Governance: new development concept. With the development of economy and society, China's rural areas have higher requirements for green development and innovative development. With the new development concept, the government's orientation of poverty alleviation and governance has also made positive adjustments. In the practice of poverty alleviation and governance, the government often needs to face the bottleneck problems such as the environmental bearing limit. It is of great significance to strengthen the construction of rural ecological environment. With the deepening of poverty alleviation and governance, the key to agricultural modernization depends on the progress of science and technology. Agricultural science and technology innovation plays an important role in agricultural modernization. The construction of smart agriculture has become the main link in the construction system of smart country. Agricultural innovation and development has been placed in a prominent position in the national science and technology innovation deployment. Scientific and technological innovation is the basic driving force of agricultural modernization and the foundation of building a high-quality agricultural system, including all aspects of modern agricultural production system and circulation system. The important adjustment of the government's poverty alleviation and governance orientation is to rely on agricultural science and technology innovation, create, introduce and apply green agricultural technology, promote the transformation of agricultural production from extensive type to saving type, and solve the agricultural environment problems And the safety of agricultural products.

Implementing the responsibility of poverty alleviation and Governance: new requirements for poverty alleviation. In the front-end stage, the micro level requires the government to accurately identify the poor groups, effectively monitor and scientifically evaluate the distribution of poverty in various regions, and strengthen the statistical and monitoring responsibilities in the field of poverty alleviation. On the macro level, the government is required to maintain the stability and sustained and rapid development of agricultural economy at the macro level, so as to provide a favorable economic environment for poverty alleviation. In the middle end docking stage, firstly, the government needs to provide basic social relief for the poor groups due to illness and disability to ensure their basic living needs; secondly, promote the construction of agricultural infrastructure projects to improve the agricultural ecological environment; thirdly, promote the high-quality and sustainable development of agriculture, and improve the scientific and technological added value of agricultural products through industrial integration and intelligent agriculture construction Finally, strengthen agricultural education and training services, improve the vocational skills and cultural literacy of rural labor force, and absorb agricultural population employment. In the end promotion stage, according to the practice of poverty alleviation, we adjust the poverty alleviation strategy, propose to build a policy support system for sustainable poverty alleviation, encourage the construction of agricultural financial platform for poverty alleviation and rich people, and build a trading channel conducive to the transfer and transformation of agricultural intellectual property rights.

Optimizing the governance structure of Poverty Alleviation: multiple participants. The field of government's poverty alleviation governance is not limited to material relief, and the inherent requirement of comprehensive poverty alleviation is by no means to solve the problem of food and clothing. Entering a new era, it covers education, health, culture, environmental protection, employment and other key areas of people's livelihood, greatly expanding the structure of government poverty alleviation and governance. The governance structure of poverty alleviation based on the role of government governance as administrative means and social organizations participating in poverty alleviation and governance with their respective advantages as auxiliary has been enriched and optimized. In the fields of capital source, technology incubation, product circulation, environmental protection cooperation and other fields, the governance role played by social organizations has improved the effectiveness of government poverty alleviation. Under the support and guidance of the government, some regions have set up 
agricultural cooperation organizations with the goal of poverty alleviation and poverty alleviation, which has brought into play the professional and technical advantages of the members of the organization, and cultivated the organization's ability of sustainable poverty alleviation and development. At the same time, all kinds of enterprise organizations, universities and scientific research institutes actively participate in poverty alleviation within the framework of the government's poverty alleviation and governance policies, participate in the development of potential development resources in poor areas through their respective advantages, and promote the continuous improvement of the national poverty alleviation governance structure under the concept of green and innovative development.

\section{Conclusion}

Under the joint effect of rural environmental carrying capacity and agricultural science and technology promotion capacity, it is of great significance to study the governance subject of rural science and technology poverty alleviation to explore and promote the high-quality development of agriculture in China.

\subsection{Public governance subject of science and technology poverty alleviation}

the main body of agricultural science and technology poverty alleviation governance is the official governance group and its related units, including four core components. First, party and mass organizations. The governance system of modern countries is mostly realized through the governance of the ruling party. In China, the party and mass organizations are the core force of poverty alleviation through science and technology in rural areas. Based on the ruling concept of common prosperity, it puts forward the strategic goal of building a moderately prosperous society in an all-round way, and plays a role in policy formulation, policy implementation, governance evaluation and promotion of rural ecological environment protection and agricultural science and technology popularization and application The leading role of supervision and guarantee. Second, the legislature. In China, the legislature refers to the national and local people's congresses and standing committees at all levels. It is an important part of national governance. It is reflected in the governance of poverty alleviation through science and technology in rural areas from the perspective of green development. Its main role is to supervise and legislate, to formulate laws and policies related to poverty alleviation and to supervise its implementation. China's legislature embodies the state's will and line on rural poverty alleviation in the form of law, and establishes state administrative and judicial organs to ensure the smooth progress of national governance. Third, administrative organs. China's administrative organs are the State Council and local people's governments at all levels. They are the main force in the implementation of policies in the national governance system. In the field of poverty alleviation through science and technology, the agricultural, science and technology, environmental protection and other departments, which are composed or dispatched by the government, cooperate and work together under the framework of Policy Governance, and undertake specific transactional work for the governance of poverty alleviation through science and technology in rural areas. Fourth, the judiciary. China's judicial organs are state organs exercising judicial power. As the main components of judicial organs, the people's courts and people's procuratorates are responsible for division of responsibilities, cooperating with each other and restricting each other in national governance. The rule of law system is the cornerstone of the national governance system, and the legal system is an important method of national governance. From the perspective of poverty alleviation and governance, the operation of judicial power provides protection for the cause of poverty alleviation, and the judicial organs extend more and more functions and influence in maintaining the order of agricultural production and life, implementing governance power constraints, and formulating agricultural environmental protection policies.

\subsection{Non official governance subject of poverty alleviation through science and technology}

Under the guidance of the government, the unofficial governance subjects of science and technology poverty alleviation mainly participate in the governance of poverty alleviation through science and technology from two aspects. On the one hand, participate in poverty alleviation projects initiated by the government. First of all, release the information of poverty alleviation needs of science and technology on the public platform of the government home, guide social forces to accurately match the needs of poverty alleviation, especially in the aspect of innovative resource allocation, guide professional people to do professional things; secondly, according to the poverty alleviation needs of different regions and time periods, establish a public project library, guide the orderly docking of innovation resources, and improve the reliability of project construction Finally, we should build agricultural demonstration areas and agricultural industrialization bases at all levels to play a role in the governance of non official science and technology poverty alleviation, provide a bearing area and project platform, and further shorten the distance between agricultural science and technology from laboratory to field. On the other hand, it will lead the construction of some poverty alleviation and development projects. First of all, in areas where the task of poverty alleviation and development is heavy and the development conditions are complex, we should mobilize the enthusiasm of the whole regional development led by unofficial poverty alleviation and governance resources. The main body of official governance is to serve well, supervise the implementation and protect the 
environment, so as to provide necessary conditions for social forces to participate in poverty alleviation. Secondly, the development of non official poverty alleviation and governance leads to the development of industrial chain. Under the background of modern agricultural development with the integration of three industries, leading enterprises have the technical and management capabilities to reshape the industrial chain, optimize the allocation of industrial resources and improve the added value of industries. Such a development model is also conducive to the formation of regional brands and the promotion of sustainable income increase. Finally, through the way of agricultural poverty alleviation development fund, the development of industrial chain is promoted, To promote the development of agricultural industrialization, social subjects have higher professionalism and sensitivity in investment in agricultural science and technology, layout of agricultural emerging industries and allocation of agricultural financial resources, which is conducive to the allocation of agricultural financial resources to the forefront of agricultural science and technology innovation, and the transformation and promotion efficiency of scientific and technological achievements is higher.

\section{References}

Zhuang T, Yuan Y, Luo M . Analysis on the Behavioral Framework of Science and Technology Poverty Alleviation of Rural Technicians, Based on the Perspective of Information Asymmetry[C]// 0.

Wei L, Ling Y, Yi S U, et al. The Research of the Rural Poverty Alleviation Path and Model of Science and Technology Based on the Peasants' Economic Behavior[J]. Hub Agricultural ences, 2017.

Ying B . Achievements and Recommendations on Poverty Alleviation through Science and Technology in Jiangsu Province[J]. Journal of Anhui Agricultural ences, 2017.

Weijun L , Li M A, Weinan L . Barrier Factors of Poverty Alleviation through Agricultural Science and Technology in Guangdong Province[J]. Tropical Agricultural Engineering, 2017.

Xiang-Rong G, Government S O , University P. Study on the Public Participation in the Process of Public Policy_ in the View of the Theory of Governance and Good Governance[J]. Journal of Shanghai Economic Management College, 2013.

Dehua Q , Cungui H E, Zongxian C, et al. Syudy on Poverty Alleviation Countermeasure of Science and Technology in Gansu[J]. Gansu Agricultural Science \& Technology, 2016.

Lin C . History, achievements and recommendations on helping the impoverished thru sci-tech program in Fujian province[J]. Fujian Journal of Agricultural ences, 2011.

Hao L I, Shiping L I, Ling N . Why Farmers' Higher Willingness of Agricultural Environmental Protection Results in Lower Behavior?_-New Insights from Fairness Perception[J]. Journal of Huazhong Agricultural University(Social ences Edition), 2018.

Author: Ni yuan (1989 -), male, Anhui Tongling, Doctor of public administration of University of Science and Technology of China, Main research direction: Poverty alleviation through science and technology; Environmental management. 